Research Article

\title{
Effect of Prior Cyclic Loading on Triaxial Compression Strength of Sliding Zone Soil of the Huangtupo Landslide
}

\author{
Qiong Chen (D), Deshan Cui $\mathbb{D}^{\mathrm{D}}$, Yu Chen, Xianyu Tao, and Wei Xiang \\ Faculty of Engineering, China University of Geosciences, Wuhan 430074, Hubei, China \\ Correspondence should be addressed to Deshan Cui; cuideshan@cug.edu.cn
}

Received 16 March 2021; Revised 10 October 2021; Accepted 26 October 2021; Published 20 November 2021

Academic Editor: Yang Wu

Copyright ( 2021 Qiong Chen et al. This is an open access article distributed under the Creative Commons Attribution License, which permits unrestricted use, distribution, and reproduction in any medium, provided the original work is properly cited.

\begin{abstract}
Earthquakes or cyclic loadings cause significant changes in the strength characteristics of soil. These changes, especially for sliding zone soil, can lead to catastrophic landslides. Taking into account this characteristic, this paper investigates the effects of prior cyclic loading on the consolidated undrained triaxial compression strength of sliding zone soil with the KTL triaxial automated system. Our experimental results indicate that the prior cyclic loading has a significant effect on the strength behaviour of saturated sliding zone soil. Under different confining pressures, cycle periods, and number of cycles, the samples exhibit the characteristics of strain-hardening. Deviatoric stress under cyclic loading condition is smaller than that with monotonic loading condition under different confining pressures, cycle periods, and number of cycles. As the confining pressure and cycle period increase, the failure stress ratio decreases. The axial strain exhibits a steep rise first and then stays stable under a cycle period of $90 \mathrm{~s}$, while the axial strain shows a linear increase with an increase in the number of cycles under a cycle period of $10 \mathrm{~s}$ under confining pressures of $100 \mathrm{kPa}$ and $400 \mathrm{kPa}$, respectively. The logarithmic relation correlates well with the failure stress ratio in the cyclic loading tests, which preliminary validates the applicability of logarithmic relation for sliding zone soil influenced by prior cyclic loading, providing a theoretical basis and guidance for the further understanding of strength characteristics of sliding zone soil.
\end{abstract}

\section{Introduction}

The Hubei Yangtze River Economic Belt, located in the center of the Yangtze River basin, is the demonstration zone for the emergence of ecological civilization in central China. Therefore, it is essential to study the catastrophic mechanism and prevention technology of landslide disasters in the Three Gorges Reservoir Area (TGRA) of the Hubei Yangtze River Economic Zone. The cyclic stress amplitudes and loading sequences on soil did affect the characterization of soil [1-4]. In particular, there is an urgency to investigate the catastrophic mechanism of landslide under cyclic loadings, such as atmospheric rainfall, the rise or fall of reservoir water levels, and especially, traffic loadings and earthquakes. The influence of periodic rainfall infiltration on sliding mass is mainly reflected in the dynamic process of increasing bulk density and attenuated matric suction, both of which lead to a lowered landslide stability safety factor [5]. The rise or fall of reservoir levels results in periodic changes in the phreatic line and affects the seepage force of groundwater [6]. The dynamic loading caused by expressways and railways leads to the accumulated deformation of landslide mass [7]. During an earthquake, the slip mass produces horizontal and vertical inertial forces under the action of earthquake acceleration, which eventually results in a landslide $[8,9]$. In addition, a higher magnitude earthquake may yield landslide in the stage of cumulative failure deformation under microseisms, and it also has the tendency to cause integral sliding deformation [10].

As the properties of sliding zone soil control the stability of landslide, a lot of in situ and indoor static strength tests on sliding zone soil have been carried out by scholars, including a direct shear test [11], triaxial compression test [12], ringshear test [13], rheological test [14], and dynamic strength test, such as hollow cylinder test and dynamic triaxial test [15]. Monitoring data [16] shows that the Huangtupo landslide is in creep state, and the sliding zone soil is in residual strength state. For a slowly sliding landslide, the sliding zone soil is in the state of residual strength, which is generally $70 \%$ of the shear strength $[17,18]$. The residual 
strength is further reduced under the action of earthquake [19]. Thereby it is urgent to study the dynamic response of the sliding zone soil in this residual strength state and analyze the catastrophic mechanism of the landslide under cyclic loading.

Currently, there are many ongoing studies on the formation mechanism of landslide in the Three Gorges Reservoir Area. Studies of the influence of cyclic loading with long period, small amplitude, and multifrequency on sliding zone soil with residual strength state, however, are scarce. The cyclic loading is likely to trigger more landslides. Therefore, on the basis of previous research results, this paper exhibits the experimental research carried out on the strength and deformation characteristics of sliding zone soil under different confining pressures, different cycle periods, and different number of cycles, in order to better explain the deformation mechanism of the Huangtupo landslide.

\section{Landslide Investigation}

The Huangtupo landslide is located in Xinling Town, Badong County, Hubei Province (Figure 1). According to a preliminary investigation, detailed investigation, and expert argumentation by the Changjiang Water Resources Committee in 1992, the Huangtupo landslide was confirmed to be an ancient large-scale landslide accumulation with complex history, which seriously threatened the safety of lives and property of the nearby people [20]. Consequently, the Huangtupo landslide relocation project was officially launched by Badong County in February 2009. This was completed by the end of May 2017; a total of 15713 people from 4475 households relocated from the landslide mass. Houses, shopping malls, workshops, and other buildings were demolished on the landslide, leaving only the highway connected with the G348 National Highway. There are still buses and trucks passing through the road all year around, which produces continuous cyclic loading on the Huangtupo landslide.

The Huangtupo landslide, formed from the mudstone, argillaceous siltstone, and limestone strata of the Triassic Badong Formation, is a multistage geological hazard mass composed of paleo-landslide mass and landslide accumulation mass. The Huangtupo landslide is composed of No. 1 and No. 2 riverside sliding masses distributed along the river. This super large and super deep paleo-landslide deposit has an area of $135.8 \times 10^{4} \mathrm{~m}^{2}$ and a volume of $6934 \times 10^{4} \mathrm{~m}^{3}$. The No. 1 riverside sliding mass takes up an area of $32.5 \times 10^{4} \mathrm{~m}^{2}$ and has a volume of $2255.5 \times 10^{4} \mathrm{~m}^{3}$, an average thickness of $69.4 \mathrm{~m}$, and a maximum thickness of $95.27 \mathrm{~m}$. At the end of 2012, the China University of Geosciences (Wuhan) built a large field comprehensive test site in Badong County on the No. 1 riverside sliding mass to study the evolution mechanism of landslides, which includes a $908 \mathrm{~m}$ long main tunnel and 5 test branches of different lengths [16]. The tunnel had a horseshoe shaped section of $5 \mathrm{~m} \times 3.5 \mathrm{~m}$. Monitoring data on surface deformation, test tunnel deformation, and deep deformation within the Huangtupo landslide revealed that the sliding zone soil is subject to low frequency and long period cyclic loading under the actions of reservoir level rise or fall and cyclic loading by traffic. Therefore, to be able to produce a stability analysis and deformation evolution of the Huangtupo landside, it is of great significance to study the stress-strain relationship of sliding zone soils under different confining pressure, cycle periods, and number of cycles.

\section{Experimental Setup and Materials}

3.1. Specimen Preparation. The sample used in this test is sliding zone soil from the $3^{\#}$ test branch of No. 1 riverside sliding mass of the Huangtupo landslide, and its basic physical and mechanical property indexes are shown in Table 1. Results of XRD analysis show that the main mineral components of the sliding zone soil are Calcite (30\%), Quartz (20\%), Illite (29\%), Montmorillonite (11\%), Chlorite (5\%), and Feldspar (5\%). The grain size distribution curve of the sliding zone soil is demonstrated in Figure 2, showing a large number of coarse-grained groups in the sliding zone soil. Coarse-grained groups play an important role in mechanical behaviour [21-23]. In order to retain the coarsegrained components as much as possible and truly reflect the composition of sliding zone soil, a sample with $61.8 \mathrm{~mm}$ diameter and $125 \mathrm{~mm}$ height was chosen.

The preparation and saturation of samples were performed in the laboratory as shown in Figure 3. A mass of $10 \mathrm{~kg}$ sliding zone soil was weighed, air-dried, crushed, and sieved to reach a maximum allowable particle size of $6.18 \mathrm{~mm}$. After measuring the moisture content removed by air drying, the required water volume was calculated, and purified water was evenly sprayed on the dried sample. The soil samples were put into a plastic bucket and sealed for $24 \mathrm{~h}$. Soil samples were weighed and compacted in five layers according to the dry density of natural samples. After each layer was compacted to the required height, the surface was roughened, and the second layer of soil sample was added until the last layer was compacted. The saturator with a sample was placed in a suction cylinder for air extraction. When the vacuum pressure was close to $-101.3 \mathrm{kPa}$, the vacuum-control state was continued for $10 \mathrm{~h}$, and then the purified water was slowly injected. When the saturator was completely submerged by water, vacuum-control device was stopped, the vacuum of the extraction cylinder was released, and the sample was kept saturating for $24 \mathrm{~h}$.

3.2. Test Procedure. The instrument used in the test was the KTL triaxial automated system developed by Xi'an KTL Instruments Company Limited. The instrument consists of a motor-controlled loading frame, a triaxial pressure chamber, load and pore pressure sensors, an eight-channel data acquisition instrument, a pressure volume controller, and other components, as shown in Figure 4.

The single loading test is consolidated undrained triaxial compression test; the test procedures are as follows:

(1) Calculate the $B$-value until it is equal to or greater than 0.95 .

(2) Consolidation. Considering the buried depth of sliding zone soil, the confining pressures are 


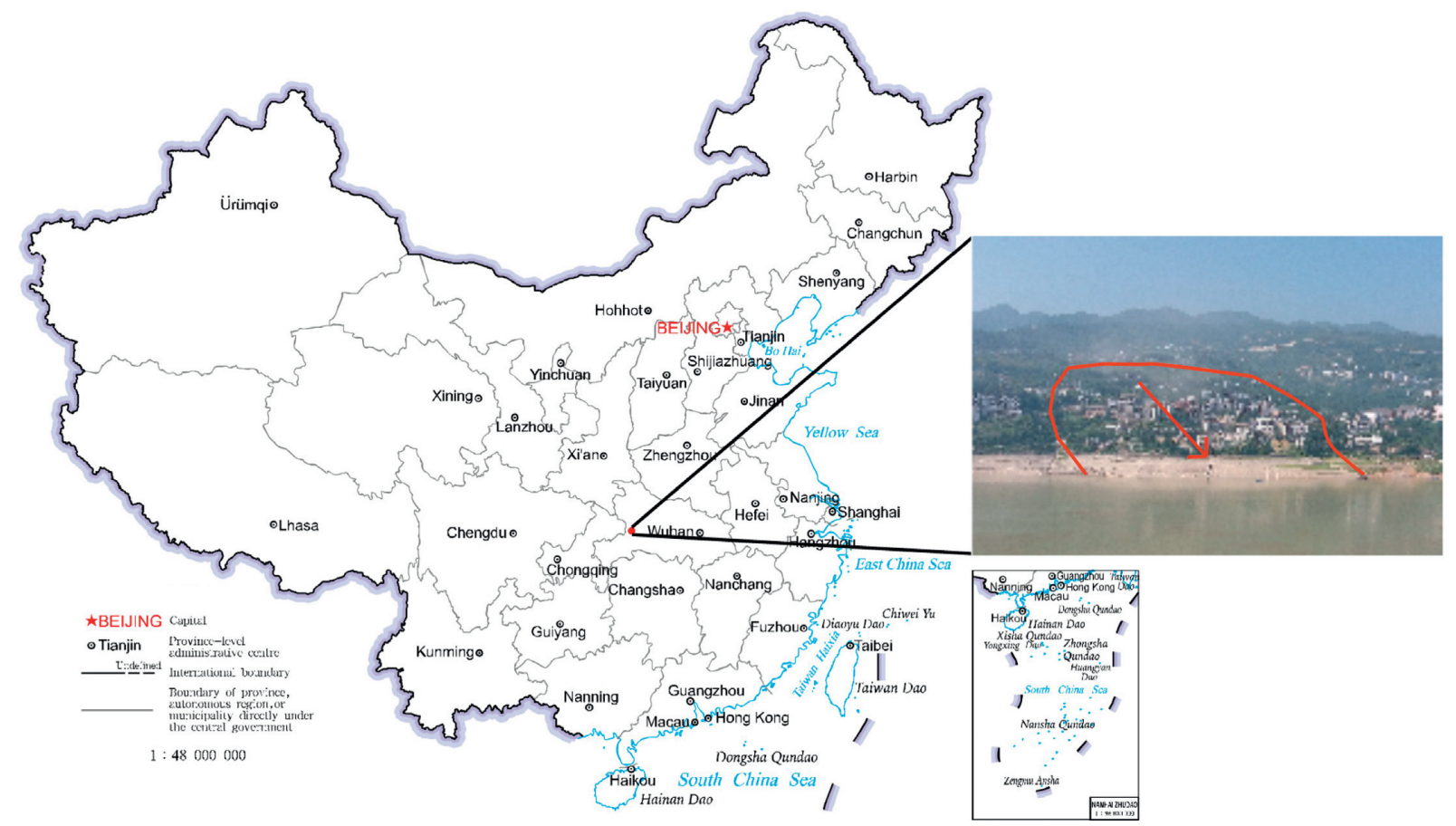

FIgURE 1: The Huangtupo No. 1 riverside sliding mass.

TABLe 1: Basic physical and mechanical properties of sliding zone soil.

\begin{tabular}{|c|c|c|c|c|c|c|}
\hline $\begin{array}{l}\text { Natural moisture } \\
\text { content w (\%) }\end{array}$ & $\begin{array}{c}\text { Natural density } \rho \\
\left(\mathrm{g} \cdot \mathrm{cm}^{-3}\right)\end{array}$ & $\begin{array}{c}\text { Specific } \\
\text { gravity (Gs) }\end{array}$ & Liquid limit (wL) & Plastic limit (wP) & Cohesion $(\mathrm{c} / \mathrm{kPa})$ & $\begin{array}{c}\text { Internal } \\
\text { friction angle } \varphi\left(^{\circ}\right)\end{array}$ \\
\hline 13.85 & 2.15 & 2.67 & 36.02 & 17.51 & 27.50 & 17.80 \\
\hline
\end{tabular}

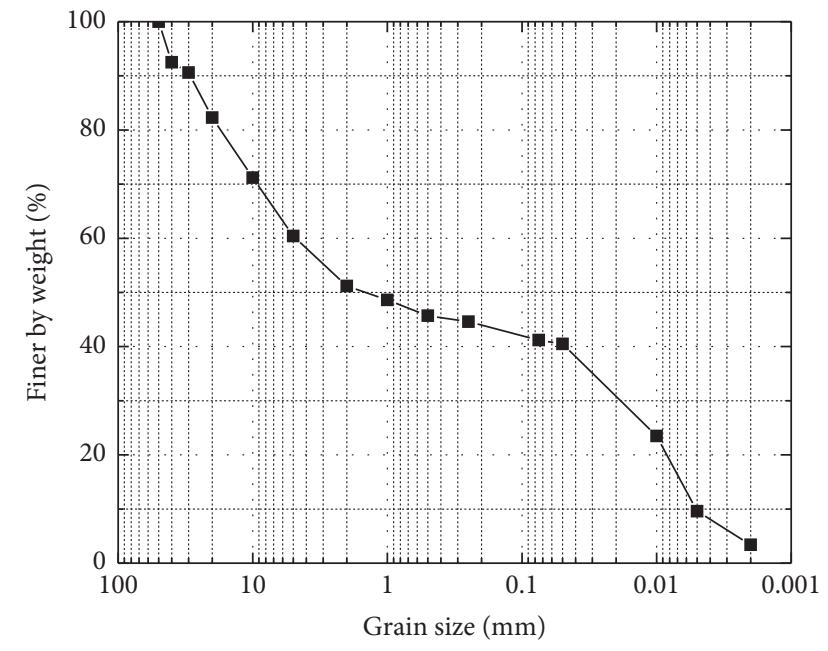

Figure 2: Particle size distribution curve of sliding zone soil.

designed to be $100 \mathrm{kPa}, 200 \mathrm{kPa}$, and $400 \mathrm{kPa}$, respectively. The loading rate is $10 \mathrm{kPa} / \mathrm{min}$. Once the confining pressure is stabilized, the drainage rate of sample is monitored. When the drainage rate is less than $0.01 \mathrm{~mm}^{3} / \mathrm{min}$, the main consolidation stage is completed.

(3) Close the drain valve and start the motor. When the deviatoric pressure equals $3 \mathrm{kPa}$, it means that the load sensor contacts with the sample top. Record the axial displacement and calculate the height of the sample after consolidation.

(4) Load and set the axial strain rate to $0.06 \% / \mathrm{min}$ until the axial strain reaches $20 \%$.

As for cyclic loading, the test procedures are as follows:

(1) Firstly, determine the shear strength.

(2) When the deviatoric stress reaches $70 \%$ of the shear strength, cyclic loading is applied. The amplitude of cyclic loading is $5 \%$ of the shear strength.

(3) Periods of $10 \mathrm{~s}, 60 \mathrm{~s}$, and $90 \mathrm{~s}$ are selected as cycle period for different cyclic loading tests. The numbers of cycles are 10,100, and 1000, respectively.

(4) If the axial strain of the specimen is less than $20 \%$ after cyclic loading, continue to load the specimen at the rate of $0.06 \% / \mathrm{min}$ until the axial strain reaches $20 \%$.

(5) When shear is completed, reduce the confining pressure and pore pressure to zero, turn off the motor, remove the pressure chamber cover, and describe the shape of the specimen after failure.

The specific test scheme is shown in Table 2.

According to creep test results, the residual strength $\left(q_{r}\right)$ of the sliding zone soil was determined as about $70 \%$ of the shear strength [13]. When the deviatoric stress reached $70 \%$ 


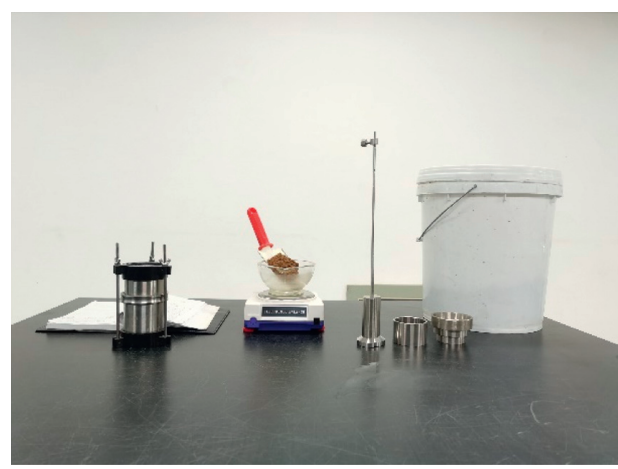

(a)

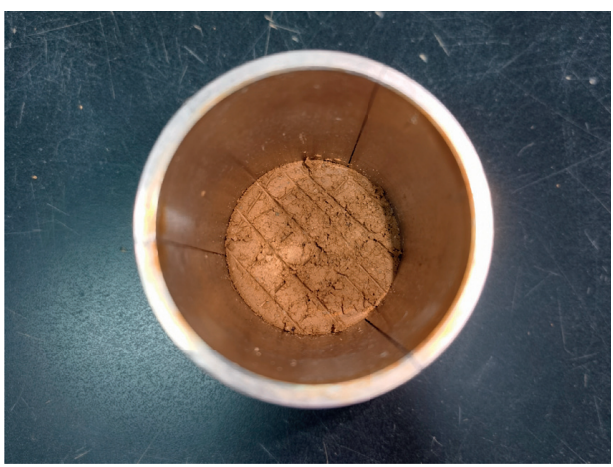

(b)

FiguRE 3: The procedures for preparing triaxial samples. (a) Sample weight. (b) The top of each layer was scarified prior to adding the next layer.

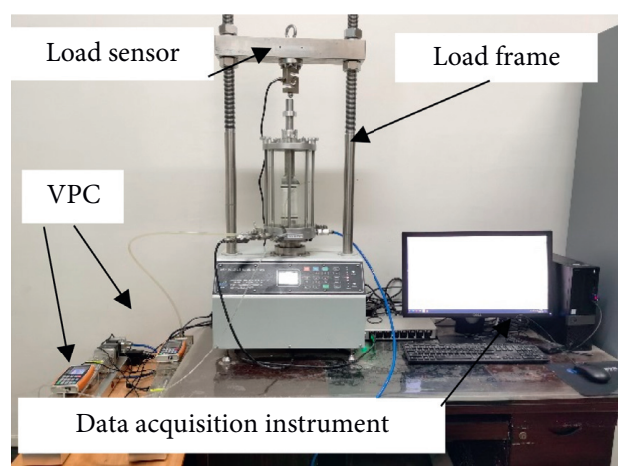

(a)

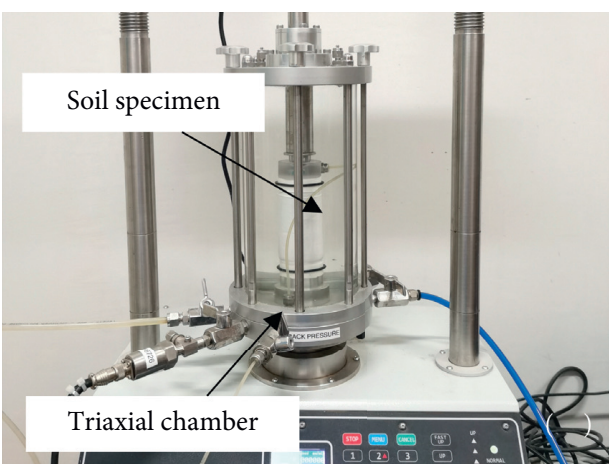

(b)

FIgURE 4: The KTL triaxial automated system. (a) Components of the triaxial compression apparatus. (b) Mounting of specimen.

Table 2: Programme of the consolidated undrained triaxial compression test.

\begin{tabular}{lccc}
\hline Sample number & Confining pressure $\sigma_{3}(\mathrm{kPa})$ & Cycle period $T(\mathrm{~s})$ & Number of cycles $N$ (times) \\
\hline S-1-1 & 100 & 0 & 0 \\
S-2-1 & 200 & 0 & 0 \\
S-4-1 & 400 & 0 & 0 \\
C-1-90-1 & 100 & 90 & 10 \\
C-1-90-2 & 100 & 90 & 100 \\
C-1-90-3 & 100 & 90 & 1000 \\
C-1-60-1 & 100 & 60 & 10 \\
C-1-60-2 & 100 & 60 & 100 \\
C-1-60-3 & 100 & 60 & 1000 \\
C-1-10-1 & 100 & 10 & 10 \\
C-1-10-2 & 100 & 10 & 100 \\
C-1-10-3 & 100 & 10 & 1000 \\
C-2-10-1 & 200 & 10 & 100 \\
C-2-60-1 & 200 & 60 & 100 \\
C-2-90-1 & 200 & 90 & 100 \\
C-4-10-1 & 400 & 10 & 100 \\
C-4-60-1 & 400 & 60 & 100 \\
C-4-90-1 & 400 & 90 & 100
\end{tabular}

of the shear strength, cyclic stress was applied to the specimen, and the stress amplitude $\left(q^{\text {amp }}\right)$ was $5 \%$ of the shear strength. Subsequently, the influence of confining pressure $\left(\sigma_{3}\right)$, cycle period $(T)$, and number of cycles $(N)$ on the strength characteristics of sliding zone soil was studied.
Under the consolidated undrained condition, cyclic loading can change the pore water pressure and the internal structure of sliding zone soil, resulting in a reduction of shear strength. To compare the stress difference of monotonic loading and multistage loading, the failure stress ratio 
$R_{f}$ is defined as shown in the following equation and is used to study the influence of prior stress on sliding zone soil strength characteristics.

$$
R_{f}=\frac{\left(q_{f}-q_{c f}\right)}{q_{f}}
$$

where $q_{f}$ indicates consolidated undrained compressive strength under monotonic loading and $q_{\mathrm{cf}}$ denotes consolidated undrained compressive strength under cyclic loading. The cyclic failure stress ratio $R_{f}$ can reflect the influence of cyclic loading on the consolidated undrained strength of sliding zone soil.

The typical triaxial test scheme is shown in Figure 5. The test process can be divided into three stages: (I) static loading stage with strain-controlled mode; (II) cyclic loading stage with stress-controlled mode; and (III) static loading stage with strain-controlled mode.

\section{Results and Discussion}

4.1. Monotonic Loading Test. Firstly, a strain-controlled consolidated undrained triaxial compression test was carried out to obtain the stress-strain curve and shear strength of sliding zone soil. For confining pressures of $100 \mathrm{kPa}$, $200 \mathrm{kPa}$, and $400 \mathrm{kPa}$, the stress-strain curves are shown in Figure 6. The stress-strain curves clearly show strainhardening characteristics, and there is no obvious peak strength in the curves. Failure stress $\left(q_{f}\right)$ is often taken to correspond to the deviatoric stress at $15 \%$ axial strain. The shear strength of the saturated sliding zone soil under three different confining pressure is $219.70 \mathrm{kPa}, 229.89 \mathrm{kPa}$, and $252.19 \mathrm{kPa}$, respectively. When the confining pressure is $100 \mathrm{kPa}$ and $200 \mathrm{kPa}$, respectively, the pore water pressure increases during axial loading process, which indicates that the sliding zone soil is in the state of contractancy, and the effective shear strength is $219.36 \mathrm{kPa}$ and $228.80 \mathrm{kPa}$, respectively. However, in the confining pressure of $400 \mathrm{kPa}$, the pore water pressure decreases to a negative value, indicating that the sliding zone soil is in the state of dilatancy, and the effective shear strength becomes $253.88 \mathrm{kPa}$. As the change of pore water pressure is not obvious during the process of axial loading, we aim to investigate the influence of different cycle periods and number of cycles on the shear strength from the perspective of total stress.

\subsection{Effect of Confining Pressure on Stress-Strain Curves.} Test results of the monotonic loading and cyclic loading (100 cycle times) of sliding zone soil under different confining pressures are shown in Figure 7. For cyclic loading, it apparently does not change the stress-strain curves type of sliding zone soil, which shows a strain-hardening type. Nevertheless, because of the influence of cyclic loading, the dynamic stress level is lower than static stress level. Before the cyclic loading is carried out, the static loading is performed to reach $70 \%$ of shear strength. Figure 7 shows that the axial strain does not exceed 3\% under various confining pressures when the deviatoric stress reaches $70 \%$ of shear strength.

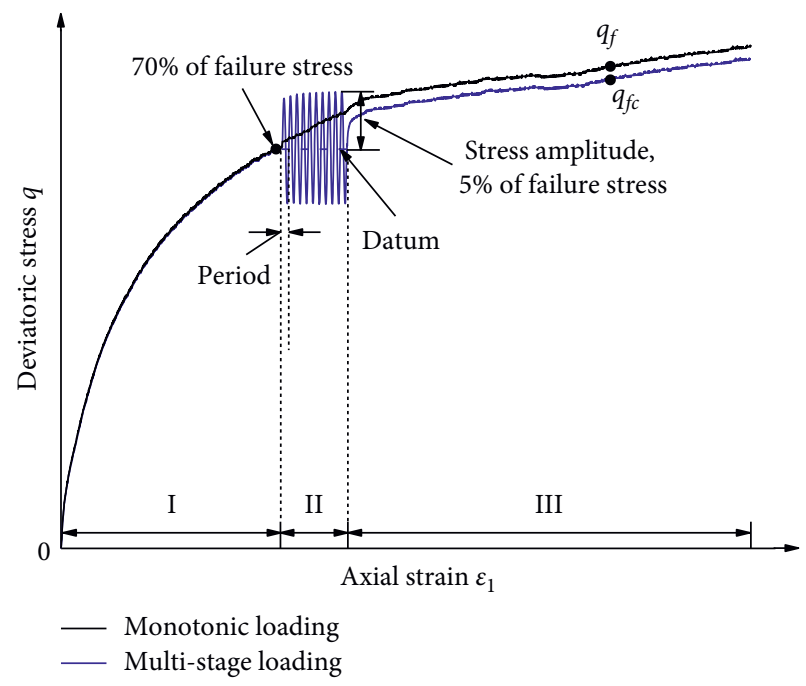

FIGURE 5: Idealized static and cyclic loading curves of sliding zone soil.

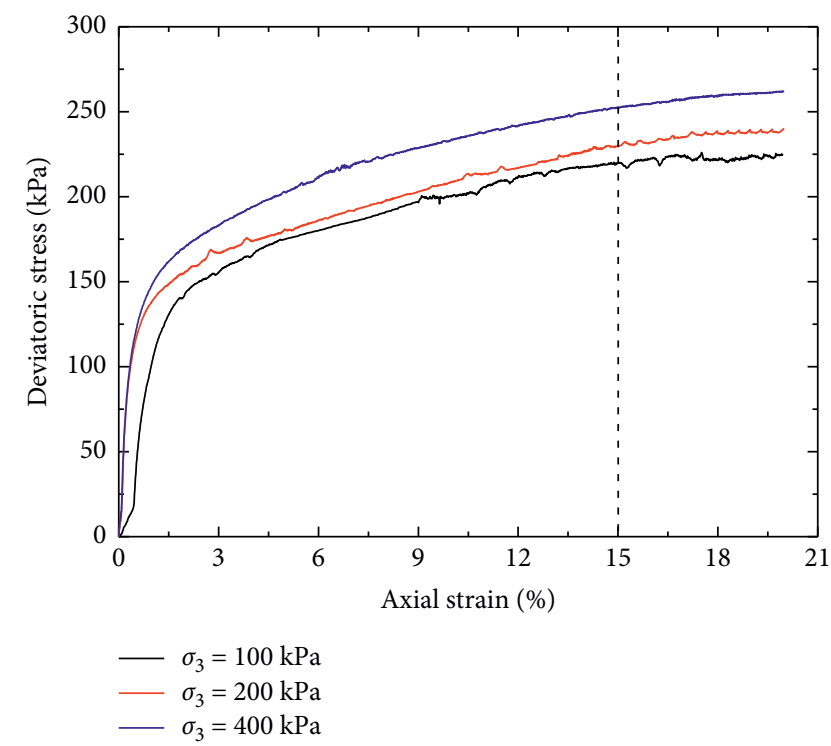

Figure 6: Stress-strain relationships of a sliding zone soil specimen under different confining pressures.

In the stage I of loading under the same confining pressure, the static loading curve is the same level. In the stage II of loading, the stress-strain curve depends on the period of cyclic loading. When the period is $10 \mathrm{~s}$, the stressstrain curve remains almost sinusoidal. With a period of $60 \mathrm{~s}$ and $90 \mathrm{~s}$, the horizontal stress-strain curve changes from sparse to dense, indicating that plastic strain in the early phase of cyclic loading is larger, and in the later phase elastic strain is obvious. In the stage III of loading, the strain-strain curve of cyclic loading is lower than that in the monotonic loading. Obviously, the prior cyclic loading reduces the ability of sliding zone soil to bear loading.

The failure stress ratio decreases with an increase in confining pressure (Figure 8). Shear strength and strength index $c$ and $\varphi$ of the sliding zone soil after 100 cycles are shown in Table 3 under different confining pressures and 

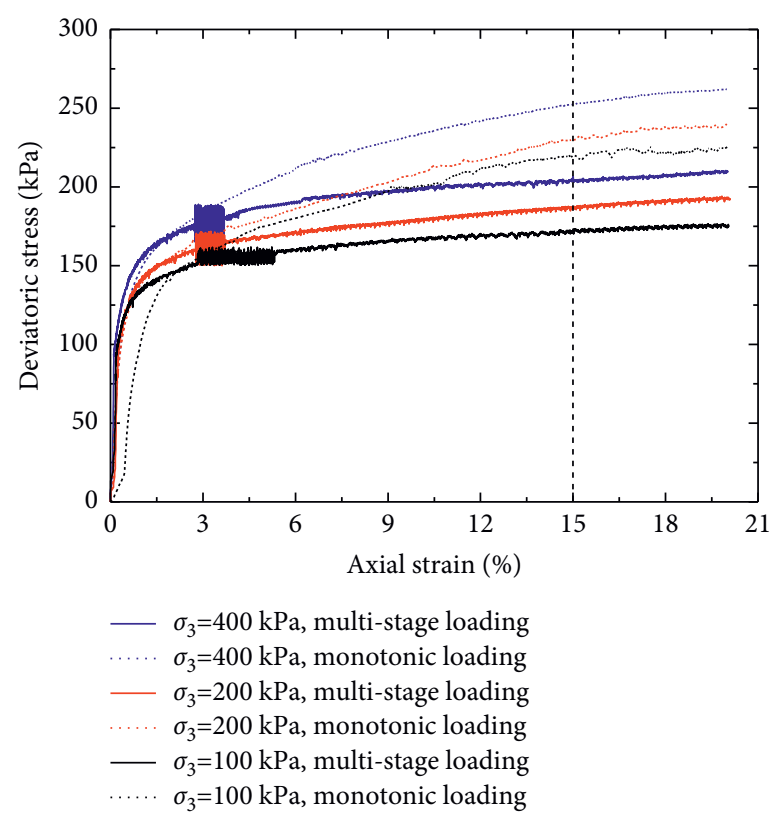

(a)

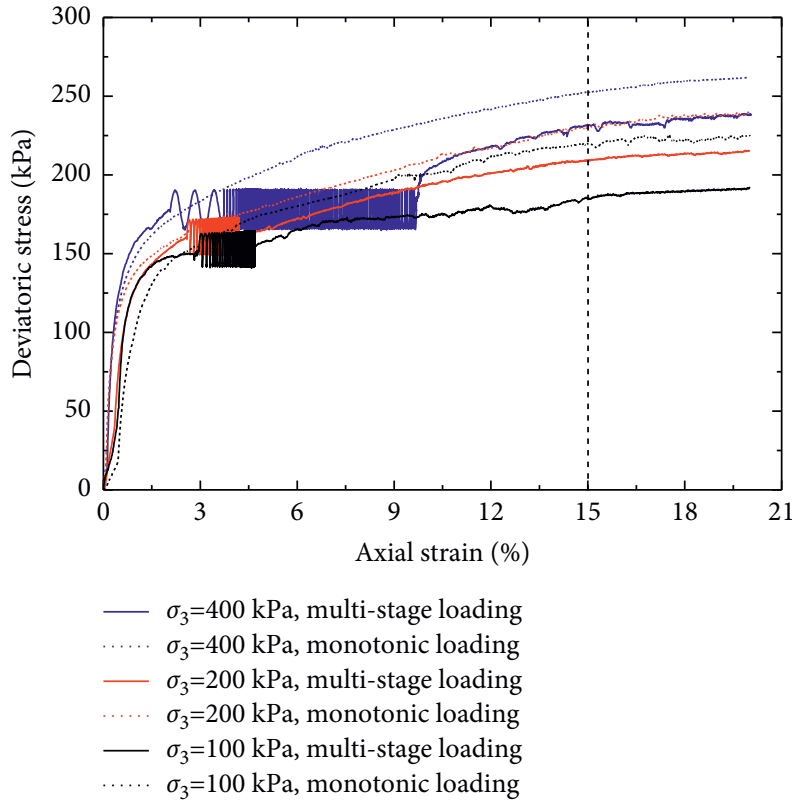

(b)

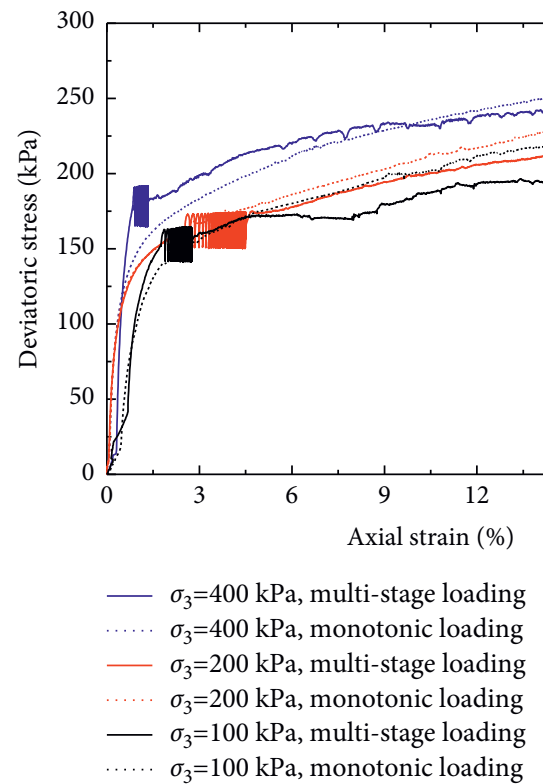

(c)

Figure 7: Deviatoric stress versus axial strain at different confining stresses $(N=100)$. (a) $T=10 \mathrm{~s}$; (b) $T=60 \mathrm{~s}$; (c) $T=90 \mathrm{~s}$.

number of cycles. It can be observed that the cohesion of sliding zone soil under cyclic loading decreases by $13.94 \%$ $21.81 \%$, while internal friction angle increases by $1.69 \%$ $35.81 \%$. Hence, cyclic loading mainly affects the cohesive strength of sliding zone soil, which makes the clay particles slide and rearrange, which decreases the bond of clay particles and increases the friction forces between particles.

The relationship between axial strain and the number of cycles under different confining pressures is shown in Figure 9. When the cycle period is $T=10 \mathrm{~s}$, total time $T_{\mathrm{t}}=10 \times 100=1000 \mathrm{~s}$ with loop 100 times, the strain versus cycle number curve shows linear growth under different confining pressures. When the cycle time is $T=60 \mathrm{~s}$, total time $T_{\mathrm{t}}=60 \times 100=6000 \mathrm{~s}$ with loop 100 times, the strain versus cycle curve under confining pressure of $100 \mathrm{kPa}$ has an attenuation stage and a stable stage, whereas the strain versus cycle curve under confining pressure of $400 \mathrm{kPa}$ shows linear increase. When the cycle time is $T=90 \mathrm{~s}$, total time $T_{\mathrm{t}}=90 \times 100=9000 \mathrm{~s}$ with loop 100 times, the strain versus cycle curve can be divided into two stages: an attenuation stage and a stable stage. Taking the confining pressures of $100 \mathrm{kPa}$ and $400 \mathrm{kPa}$ as examples, the curve exhibits a stable stage after 53 and 38 cyclic loadings, respectively. Except for the influence of cyclic period, the total time of cyclic loading has a significant impact on the strain characteristics of samples. 


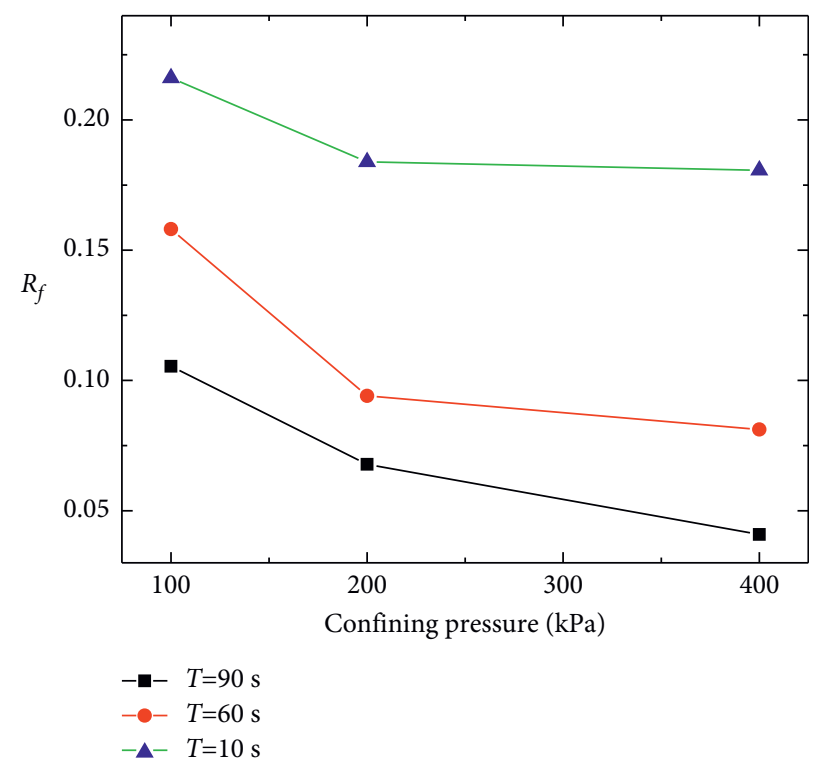

FIgURE 8: Shear strength ratio of sliding zone soil at different confining pressures $(N=100)$.

TABLE 3: Results of monotonic and multistage loading tests for 100 cycles.

\begin{tabular}{lccccc}
\hline Test category & $\begin{array}{c}\text { Cycle period } \\
(T)(\mathrm{s})\end{array}$ & $\begin{array}{c}\text { Cohesion intercept } \\
(c)(\mathrm{kPa})\end{array}$ & $\begin{array}{c}\text { Effective cohesion } \\
\text { intercept }\left(c^{\prime}\right)(\mathrm{kPa})\end{array}$ & $\begin{array}{c}\text { Internal friction } \\
\text { angle }(\varphi)(\underline{\mathrm{o}})\end{array}$ & $\begin{array}{c}\text { Effective internal friction } \\
\text { angle }(\varphi)(\underline{\mathrm{o}})\end{array}$ \\
\hline Monotonic & - & 99.03 & 89.20 & 2.96 & 1.68 \\
loading test & 90 & 85.23 & 82.60 & 3.98 & 1.03 \\
& 60 & 80.70 & 78.35 & 4.02 & 1.32 \\
Cyclic loading test & 10 & 77.43 & 69.50 & 3.01 & 1.61 \\
\hline
\end{tabular}

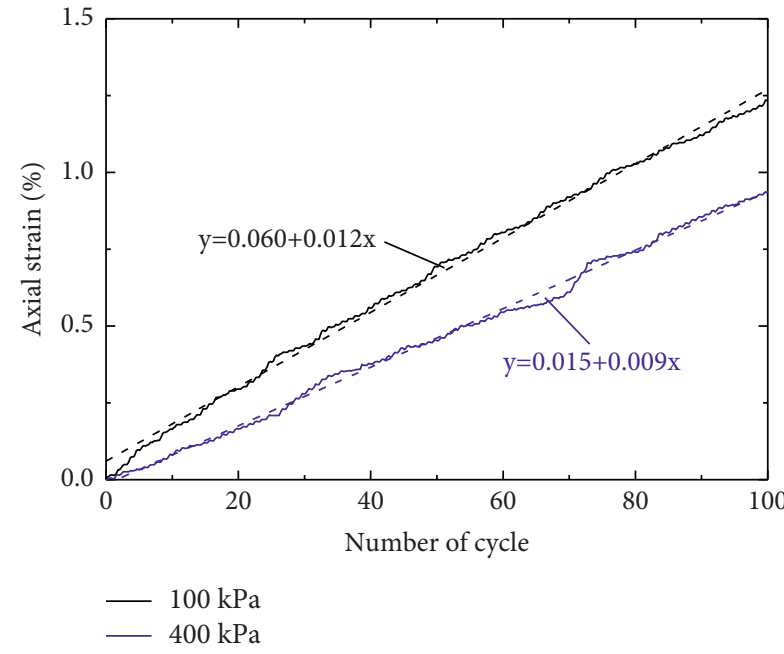

(a)

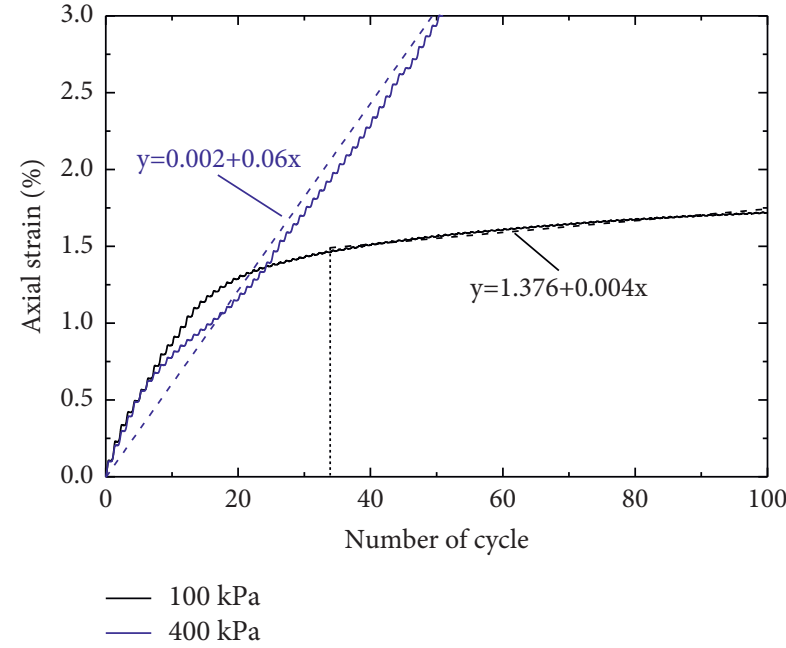

(b)

FIgURE 9: Continued. 


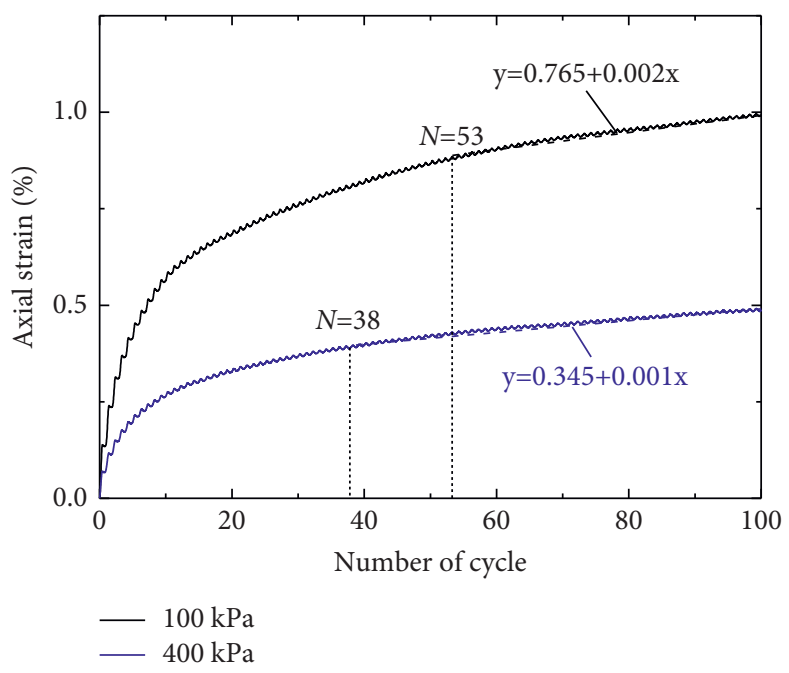

(c)

Figure 9: Curve axial strain versus number of cycles at different confining stresses under $N=100$. (a) $T=10 \mathrm{~s}$; (b) $T=60 \mathrm{~s}$; (c) $T=90 \mathrm{~s}$.

4.3. Effect of Cycle Period on Stress-Strain Curves. To further study the stress-strain characteristics of sliding zone soil under different cyclic loading and constant confining pressure of $\sigma_{3}=100 \mathrm{kPa}$, consolidated undrained triaxial compression tests with different cycle periods $(10 \mathrm{~s}, 60 \mathrm{~s}$, and $90 \mathrm{~s}$ ) and 100 cycles were carried out, as shown in Figure 10. It is observed that, under the same cycle number $(N=100)$, a short cycle period results in a decrease in shear strength, showing that the short cycle period decelerates the dissipation of excess pore water pressure and longer cycle period accelerates the dissipation of excess pore water pressure.

The cycle period has a significant impact on the failure stress ratio of samples. The increase of cycle period under the same number of cycles is followed by a reduction of failure stress ratio of samples with respect to prior cyclic loading, as indicated in Figure 11.

Taking 1000 cycles as an example, the axial cumulative strain curves of sliding zone soil under different cycle period are shown in Figure 12(a). When the specimen is subjected to a loading period of $10 \mathrm{~s}$, the axial cumulative strain increases almost linearly. A loading period of $60 \mathrm{~s}$ causes a rapid rise in the axial strain within 100 cycles, followed by a steady reduction and tending to a stable level. When the specimen is loaded under the cycle period of $90 \mathrm{~s}$, the axial strain increases rapidly within the first 60 cycles and then decreases slowly to a stable level. Figure 12(b) shows a typical dynamic stress-strain curve under $N=100$ and $T=90 \mathrm{~s}$. The axial strain of the sample is composed of elastic strain and plastic strain. For longer cycle period, during the early stage of loading, the plastic strain decreases significantly, followed by elastic strain. But for shorter cycle period, during the whole loading stage, the plastic strain remained at the same level because of the unfavorable dissipation of excess pore water pressure.

4.4. Effect of Number of Cycles on Stress-Strain Curves. Triaxial consolidation undrained tests with a confining pressure of $100 \mathrm{kPa}$ and cycles of $0,10,100$, and 1000 times

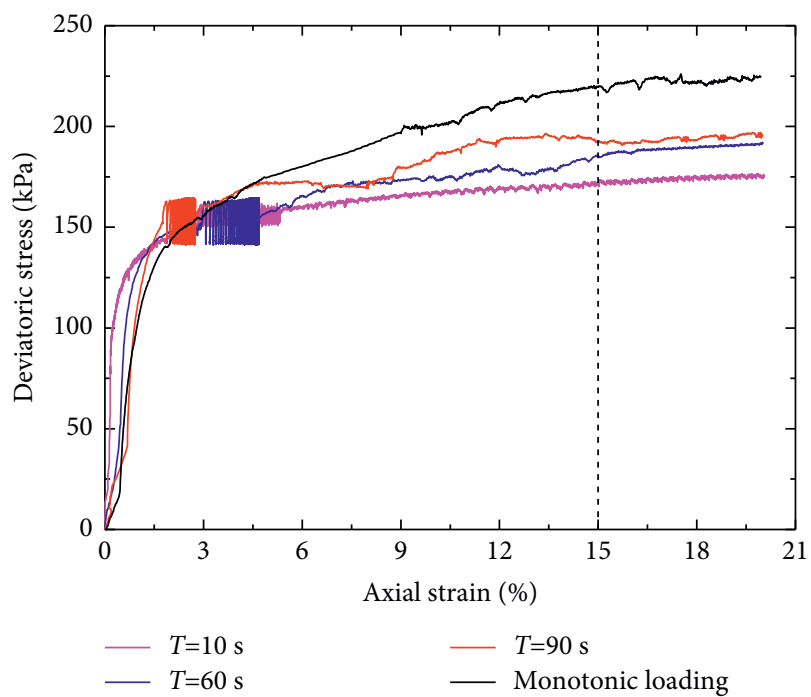

Figure 10: Curve deviator stress versus axial strain at a constant confining stress of $100 \mathrm{kPa}$ under $N=100$.

were carried out with the aim of studying the influence of different cyclic times on the strength characteristics of sliding zone soil. The acquired stress-strain relationship is shown in Figure 13. When the cycle period and stress amplitude are fixed, after being subjected to different cycle times, the stress-strain curve of sliding zone soil still shows the strain-hardening type. The shear strength shows a decline when the axial strain reaches 15\% under larger cycle times. Cumulative plastic strain increases with an increase in cycle number, but with a gradual reduction in its growth rate.

Figure 14 shows that the failure stress ratio grows as the number of cycles increases. Taking $T=90 \mathrm{~s}$ as an example, the failure stress ratio is observed to increase by $5.93 \%$, $10.54 \%$, and $12.13 \%$ after 10, 100, and 1000 loading cycles, respectively. It can be seen that the accumulated plastic strain in prior cyclic loading increases the failure stress ratio. 


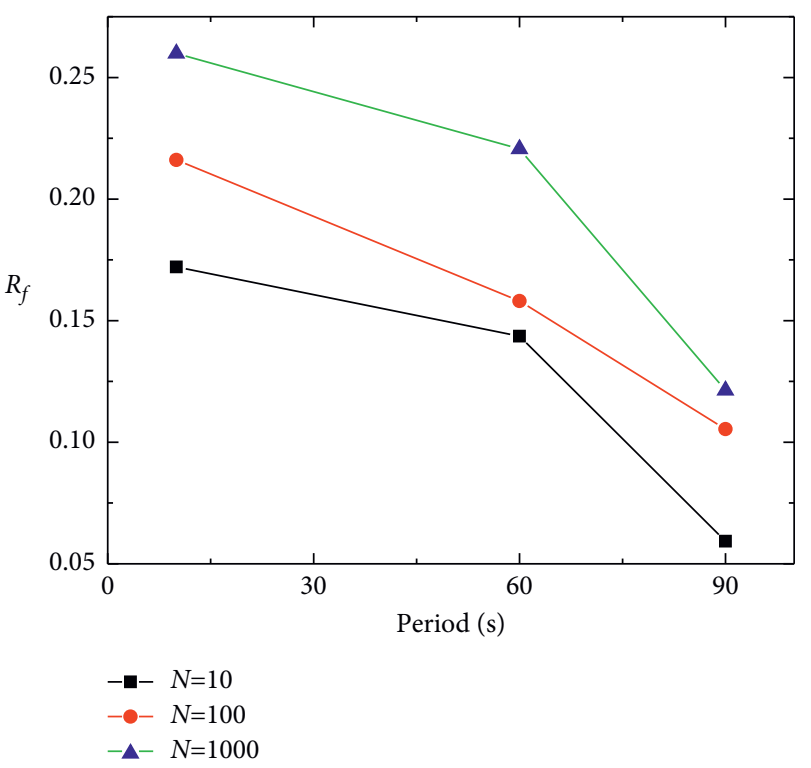

FIGURE 11: Shear strength ratio of sliding zone soil at different cycle periods $\left(\sigma_{3}=100 \mathrm{kPa}\right)$.

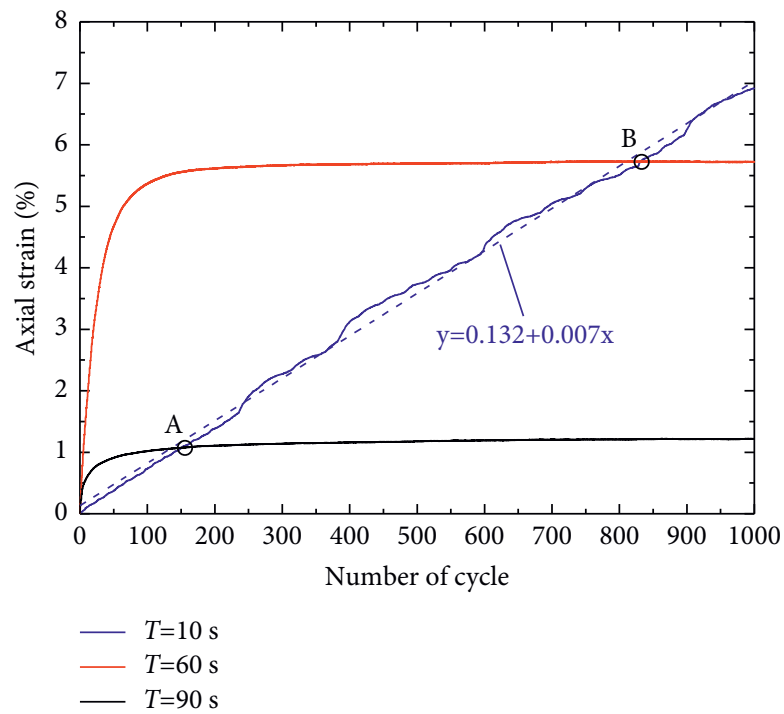

(a)

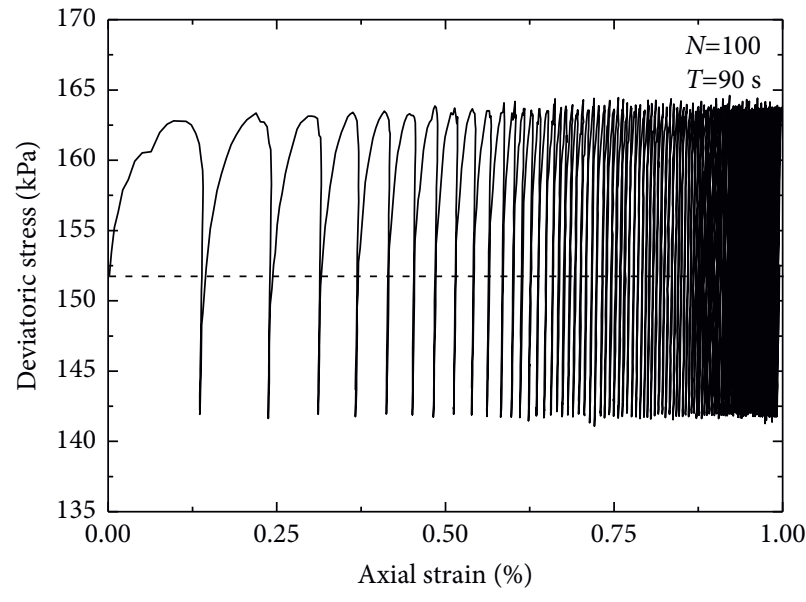

(b)

Figure 12: Effect of the number of cycles on sliding zone soil at $\sigma_{3}=100 \mathrm{kPa}$. (a) Curve axial strain versus cycle number with $N=1000$; (b) curve deviator stress versus axial strain under $N=100$.

Furthermore, the dissipation of excess pore water pressure increased the effective stress and reduced the loss of shear strength.

Curves of the failure stress ratio $\left(R_{f}\right)$ of sliding zone soil as a function of number of cycles $(N)$ show that the relationship between $R_{f}$ and $N$ approximately satisfies the following formula:

$$
R_{f}=a-b \ln (N+c),
$$

where $a, b$, and $c$ denote the fitting parameters, respectively. The logarithmic relation correlates with the failure stress ratio and the number of cycles in cyclic loading tests, which preliminary validates the applicability of logarithmic relation for sliding zone soil characteristics influenced by cyclic 

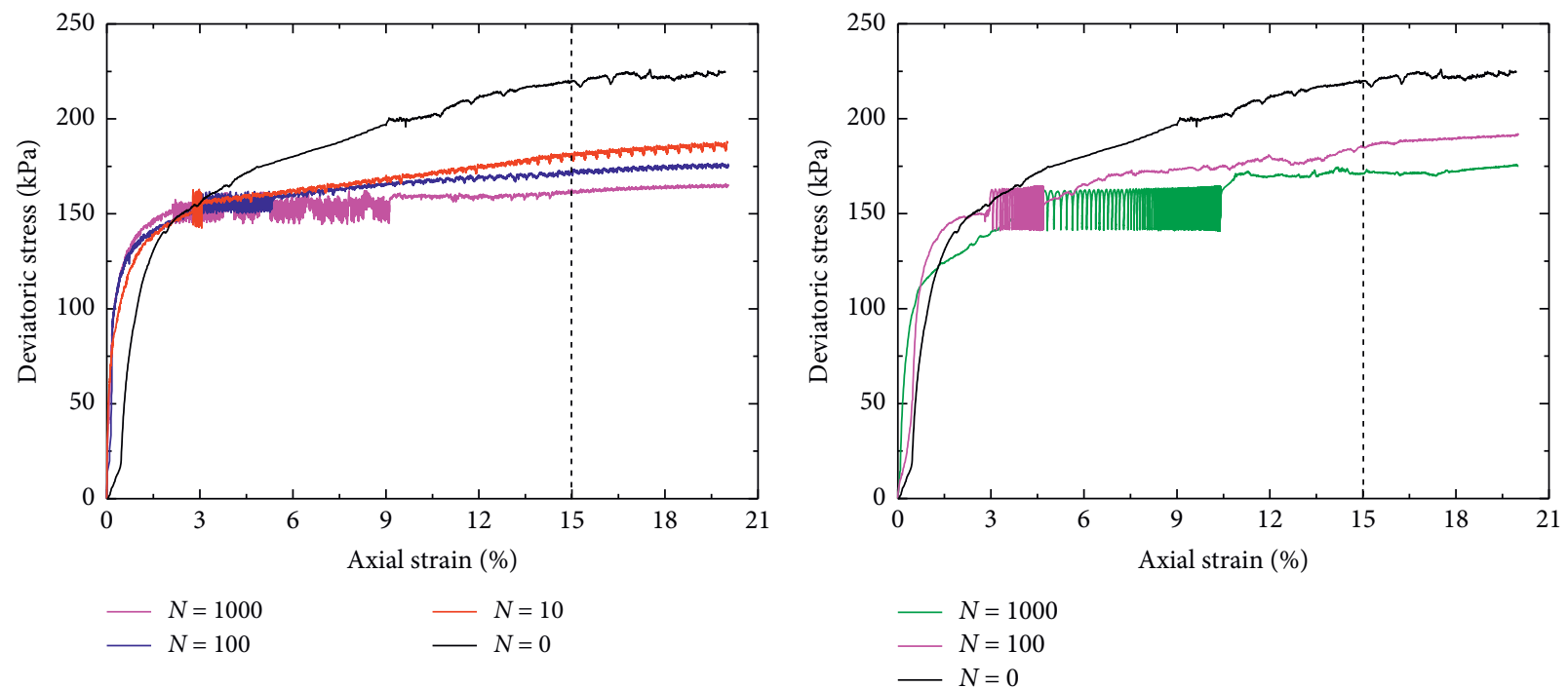

(a)

(b)

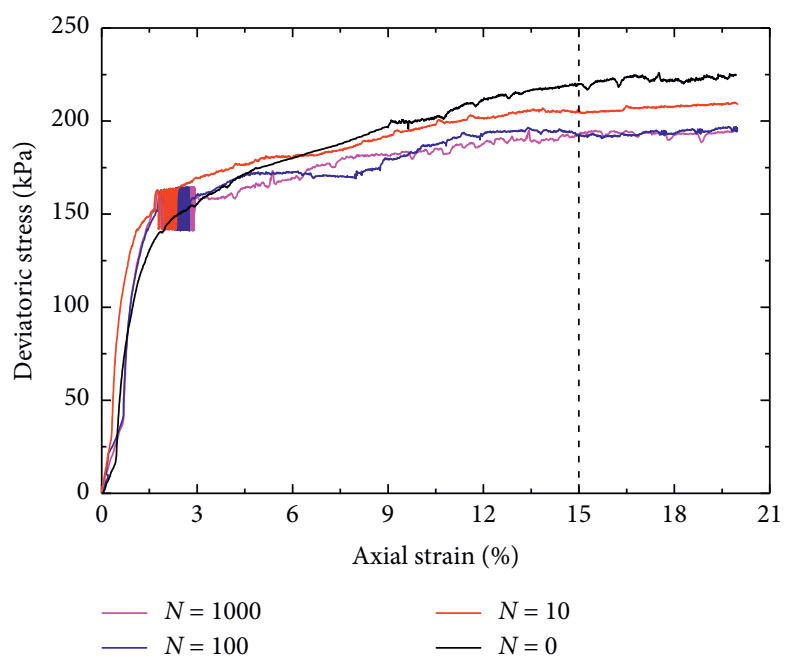

(c)

Figure 13: Deviatoric stress versus axial strain under a different number of cycles at a confining pressure of $100 \mathrm{kPa}$. (a) $T=10 \mathrm{~s}$; (b) $T=60 \mathrm{~s}$; (c) $T=90 \mathrm{~s}$

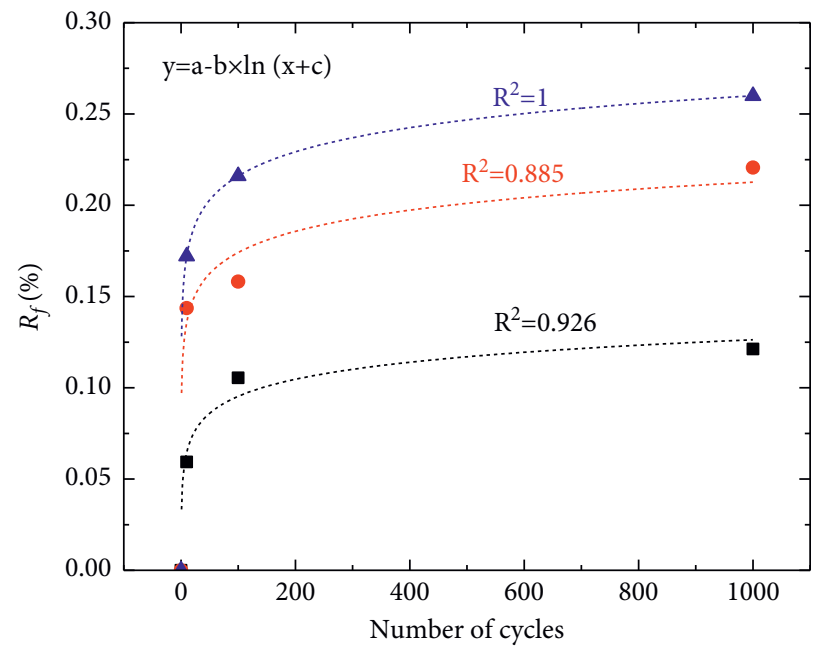

- $T=90 \mathrm{~s}$

- $T=60 \mathrm{~s}$

\ $T=10 \mathrm{~s}$

FIgURE 14: The failure stress ratio $R_{f}$ as a function of the number of cycles. 
loading, providing a theoretical basis and guidance for the further understanding of strength characteristics of sliding zone soil.

\section{Conclusions}

In an effort to investigate the influence of prior cyclic loading on sliding zone soil stress-strain behaviours under a consolidated undrained triaxial compression test, a series of monotonic loading and cyclic loading tests were designed and carried out on the basis of the KTL Triaxial Automated System. The strength and deformation characteristics of soil specimens subjected to different confining pressure, cycle periods, and number of cycles were analyzed in depth. The conclusions are as follows:

(1) For the sliding zone soil involved in the consolidated undrained triaxial compression test with different prior cycle periods and number of cycles, the stressstrain curves of monotonic loading and cyclic loading both exhibit strain-hardening characteristics.

(2) The deviatoric stress of cyclic loading is smaller than that of monotonic loading under different confining pressures because of the prior cyclic stress. As the confining pressure increases, the failure stress ratio decreases, indicating the effect of prior cyclic loading on shearing strength weakens under higher stress state.

(3) For the curves of axial strain versus number of cycles, the axial strain first exhibits a precipitous rise and then remains stable under the cycle period of $90 \mathrm{~s}$, total time $T_{\mathrm{t}}=90 \times 100=9000 \mathrm{~s}$ with loop 100 times. But the axial strain shows a linear increase with the increase of number of cycles under the period of $10 \mathrm{~s}$, total time $T_{\mathrm{t}}=10 \times 100=1000 \mathrm{~s}$ with loop 100 times. The axial strain accumulation was influenced by not only the cycle period but also the total cyclic loading time.

(4) The logarithmic relation correlates with the failure stress ratio and the number of cycles in cyclic loading tests, which preliminary validates the applicability of logarithmic relation for sliding zone soil characteristics influenced by prior cyclic loading.

\section{Data Availability}

The data used to support the findings of this study are available from the corresponding author upon request.

\section{Conflicts of Interest}

The authors declare that they have no conflicts of interests.

\section{Acknowledgments}

This work was financially supported by the National Natural Science Foundation of China (nos. 41772304 and 41602313).

\section{References}

[1] A. C. Trandafir and K. Sassa, "Performance-based assessment of earthquake-induced catastrophic landslide hazard in liquefiable soils," Geotechnical \& Geological Engineering, vol. 24, no. 6, pp. 1627-1639, 2006.

[2] P. He, S.-C. Li, J. Xiao, Q.-Q. Zhang, F. Xu, and J. Zhang, "Shallow sliding failure prediction model of expansive soil slope based on Gaussian process theory and its engineering application," KSCE Journal of Civil Engineering, vol. 22, no. 5, pp. 1709-1719, 2018.

[3] R. Nie, Y. Li, W. Leng, H. Mei, J. Dong, and X. Chen, "Deformation characteristics of fine-grained soil under cyclic loading with intermittence," Acta Geotechnica, vol. 15, no. 11, pp. 3041-3054, 2020.

[4] P. Jitsangiam, S. Pra-ai, M. Boulon, O. Jenck, X. Chen, and S. Techavorasinsakul, "Characterization of a soil-rough structure interface using direct shear tests with varying cyclic amplitude and loading sequences under a large cyclic testing cycle condition," Acta Geotechnica, pp. 1-17, 2021.

[5] H. C. Chen, Study on Dynamic Load Laws and Attenuation Laws of Parameters Induced by Rainfall of Colluvial Landslide and its Stability Evolutional Laws, Qingdao Technological University, Ph.D. Thesis, , p. 67, 2014 .

[6] R. Li and W. B. Jian, "Road landslide induced by dynamic load and water level fluctuation and its treatment," Geotechnical Engineering World, vol. 12, pp. 63-66, 2009.

[7] H. Ai, H. G. Wu, W. Q. Feng, and X. Y. Chen, "Shaking table test study on deformation and failure mechanism of landslide with multiple slip surface," Journal of Disaster Prevention and Mitigation Engineering, vol. 38, pp. 65-71, 2018.

[8] R. W. Jibson, "Methods for assessing the stability of slopes during earthquakes-A retrospective," Engineering Geology, vol. 122, no. 1-2, pp. 43-50, 2011.

[9] S. A. Sepúlveda, D. N. Petley, M. J. Brain, and N. Tunstall, "The effect of dynamic loading on the shear strength of pyroclastic ash deposits and implications for landslide hazard: the case of Pudahuel Ignimbrite, Chile," Engineering Geology, vol. 205, pp. 54-61, 2016.

[10] V. Del Gaudio and J. Wasowski, "Advances and problems in understanding the seismic response of potentially unstable slopes," Engineering Geology, vol. 122, no. 1-2, pp. 73-83, 2011.

[11] Q. Chen, D. S. Cui, J. E. Wang, and Q. B. Liu, “An experimental study of creep characteristics of sliding zone soil of Huangtupo landslide under different consolidation stresses," Rock and Soil Mechanics, vol. 41, pp. 1-8, 2020.

[12] Q. Tan, H. Tang, L. Fan et al., "In situ triaxial creep test for investigating deformational properties of gravelly sliding zone soil: example of the Huangtupo 1\# landslide, China," Landslides, vol. 15, no. 12, pp. 2499-2508, 2018.

[13] S. Wang, W. Wu, J. Wang, Z. Yin, D. Cui, and W. Xiang, "Residual-state creep of clastic soil in a reactivated slowmoving landslide in the Three Gorges Reservoir Region, China," Landslides, vol. 15, no. 12, pp. 2413-2422, 2018.

[14] D. S. Cui, Q. Chen, W. Xiang, and J. E. Wang, "Experimental study of stress relaxation characteristics of saturated sliding zone soils of Huangtupo landslide under triaxial compression," Rock and Soil Mechanics, vol. 39, pp. 209-216, 2018.

[15] E. C. Yan, H. C. Liu, and H. M. Tang, "Experimental study on the dynamic properties of soil in slide zone of landslide," Journal of Engineering Geology, vol. 11, pp. 318-322, 2003.

[16] J. Wang, A. Su, W. Xiang et al., "New data and interpretations of the shallow and deep deformation of Huangtupo No. 1 
riverside sliding mass during seasonal rainfall and water level fluctuation," Landslides, vol. 13, no. 4, pp. 795-804, 2016.

[17] S. J. Yan, W. Xiang, H. M. Tang, Z. W. Man, and R. C. Xu, "Research on creep behaviour of slip band soil of Dayantang landslide," Rock and Soil Mechanics, vol. 29, no. 58-62, p. 68, 2008.

[18] B. Wang, J. B. Zhu, H. M. Tang, and W. Xiang, "Study on creep behaviour of slip band soil of Huangtupo landslide," Journal of Yangtze River Scientific Research Institute, vol. 25, pp. 49-52, 2008.

[19] W. H. Schulz and G. Wang, "Residual shear strength variability as a primary control on movement of landslides reactivated by earthquake-induced ground motion: implications for coastal Oregon, U.S," Journal of Geophysical Research: Earth Surface, vol. 119, no. 7, pp. 1617-1635, 2014.

[20] Y.-Y. Jiao, L. Song, H.-M. Tang, and Y.-A. Li, "Material weakening of slip zone soils induced by water level fluctuation in the ancient landslides of Three Gorges Reservoir," Advances in Materials Science and Engineering, vol. 2014, no. 2, pp. 1-9, Article ID 202340, 2014.

[21] Y. Wu, H. Yamamoto, J. Cui, and H. Cheng, "Influence of load mode on particle crushing characteristics of silica sand at high stresses," International Journal of Geomechanics, vol. 20, no. 3 , Article ID 04019194, 2020.

[22] Y. Wu, N. Li, X. Z. Wang et al., "Experimental investigation on mechanical behavior and particle crushing of calcareous sand retrieved from South China Sea," Engineering Geology, vol. 280, Article ID 105932, 2021 a.

[23] Y. Wu, J. Cui, J. Huang, W. Zhang, N. Yoshimoto, and L. Wen, "Correlation of critical state strength properties with particle shape and surface fractal dimension of clinker ash," International Journal of Geomechanics, vol. 21, no. 6, Article ID 04021071, 2021b. 